\title{
Scaling left ventricular mass in adolescent female soccer players
}

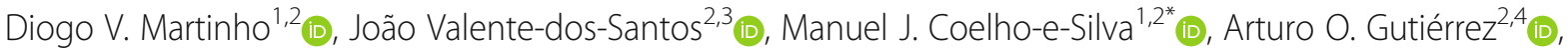 \\ João P. Duarte ${ }^{1,2}$ (D), Pedro Lourenço-Farinha ${ }^{1}$ (D), Leonardo G. O. Luz ${ }^{2,5}$ (D), João Gonçalves-Santos ${ }^{6}$ (D),

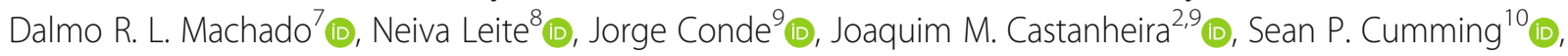 \\ Lauren B. Sherar ${ }^{11}$ (iD and Robert M. Malina ${ }^{12,13}$ (D)
}

\begin{abstract}
Background: The aim of the study was to examine the contribution of chronological age (CA), skeletal maturation, training experience and concurrent body size descriptors, to inter-individual variance in left ventricular mass (LVM) among female adolescent soccer players.

Methods: The sample included 228 female soccer players 11.8-17.1 years. Training experience defined as years of participation in competitive soccer (range 2-9years), was obtained by interview. Stature, body mass and skinfolds (triceps, medial calf) were measured. Fat mass was estimated; Fat-free mass was derived. LVM was assessed by echocardiography. Skeletal maturity status was as the difference of skeletal age (SA, Fels method) minus CA.

Results: Fat-free mass was the most prominent single predictor of $\operatorname{LVM}\left(\mathrm{R}^{2}=36.6 \%\right)$. It was associated with an allometric coefficient close to linearity ( $k=0.924,95 \% \mathrm{Cl}$ : 0.737 to 1.112$)$. A significant multiplicative allometric model including body mass, fat-free mass, CA, training experience and skeletal maturity status was also obtained $(\mathrm{R}=$ $\left.0.684 ; R^{2}=46.2 \%\right)$.
\end{abstract}

Conclusion: Stature has limitations as a valid size descriptor of LVM. Body mass, fat-free mass, training experience, CA, body mass and skeletal maturity status were relevant factors contributing to inter-individual variability in LVM.

Keywords: Youth sport, Female athletes, Growth, Cardiac function, Skeletal age, Scaling

\section{Background}

Growth refers to changes in body size, and adolescence is the interval of major changes in height, mass, proportions and composition [1]. The adolescent changes also influence the growth of specific organs, which in turn affects function. Cross-sectional [2] and longitudinal [3, 4] studies have reported that left ventricular mass (LVM) increases during childhood through adolescence. Because age-associated variation in cardiac dimensions is

\footnotetext{
* Correspondence: mjcesilva@hotmail.com

${ }^{1}$ Faculty of Sport Sciences and Physical Education, University of Coimbra, Coimbra, Portugal

${ }^{2}$ CIDAF (uid/dtp/04213/2020), University of Coimbra, Estadio Universitario, Pavilhao III, Coimbra, Portugal

Full list of author information is available at the end of the article
}

due, in part, to growth related increments in body size, LVM is routinely expressed relative to stature, mass or body surface area (BSA) [5-7]. Systematic training for specific sports during childhood and/or adolescence may influence left ventricular wall thickness (LVWT) and/or increments in the left ventricular cavity. These training adaptations may lead to challenges in diagnosing conditions such as dilated cardiomyopathy or hypertrophic cardiomyopathy [6].

The aforementioned structural and functional adaptive changes to the left ventricle have been labelled "athlete's heart" [8] with LVM being the most common indicator of these cardiac adaptations [9, 10]. Chronic volume loads generally result in an increase in end-diastolic

(c) The Author(s). 2020 Open Access This article is licensed under a Creative Commons Attribution 4.0 International License, which permits use, sharing, adaptation, distribution and reproduction in any medium or format, as long as you give appropriate credit to the original author(s) and the source, provide a link to the Creative Commons licence, and indicate if changes were made. The images or other third party material in this article are included in the article's Creative Commons licence, unless indicated otherwise in a credit line to the material. If material is not included in the article's Creative Commons licence and your intended use is not permitted by statutory regulation or exceeds the permitted use, you will need to obtain permission directly from the copyright holder. To view a copy of this licence, visit http://creativecommons.org/licenses/by/4.0/ The Creative Commons Public Domain Dedication waiver (http://creativecommons.org/publicdomain/zero/1.0/) applies to the data made available in this article, unless otherwise stated in a credit line to the data. 
diameters and by inference in LVM; these consequently contribute to eccentric hypertrophy [11]. Intra- and inter-individual variability in cardiac variables in general and LVM in particular are associated with participation in sport but observed changes vary with type of sport [12]. It is also suggested that cardiac dimensions are associated with metabolically active tissues, mainly fat-free mass (FFM) [13-15]. Among 73 male roller hockey players 14-16 years of age, for example, estimated FFM was the best single predictor of inter-individual variance in LVM [16]; however, the results also suggested that biological maturity status should also be considered alongside stature (the traditional size descriptor) to index LVM. On the other hand, there is evidence that fat mass (FM) is also an independent and positive predictor of LVM in children and adolescents not engaged in youth sport $[17,18]$.

Historically, ratio standards have been frequently used to interpret physiological and morphological dimensions among individuals, including athletes, who vary in body size and composition. Stature $(\mathrm{cm})$ and BSA $\left(\mathrm{cm}^{2}\right)$ are, respectively, linear and bi-dimensional, while body mass and FFM are tri-dimensional variables. Allometric models have been suggested as an effective option for partitioning the effects of body size in order to derive a "size free" (dimensionless) expression of physiological parameters, e.g., maximum oxygen uptake in liters [19, 20] or LVM expressed in grams [6, 16, 21]. Since variation in body mass and composition is associated with growth, maturity status and also systematic training $[1$, $22,23]$, proportional allometric models have been recommended among adult males and females [20]. Studies of youth athletes, particularly male hockey players, have addressed the independent and combined effects of variables such as chronological age (CA), maturity status (skeletal age, SA), and training experience with one or more body size descriptors (usually stature, body mass, FFM) on peak oxygen uptake [24] and LVM [16]. However, studies of LVM relative to body size have focused on adults and male adolescent athletes. Data are still lacking for female adolescent athletes.

The adolescent growth spurt differentially impacts attained stature and mass in youth of both sexes. Peak height velocity (PHV) occurs, on average, 2 years earlier in girls than in boys and tends to be less intense in girls [1]. Growth during the adolescent spurt has a marked impact on sex differences in body mass and composition. This is perhaps most marked in the linear increase in FFM among boys during adolescence, while the corresponding adolescent increase in FFM tends to reach a plateau in girls in association with a linear increase in adipose tissue. Therefore, it may be hypothesized that allometric models based on samples of male adolescent athletes may not be generalized to explain intra- and inter-individual variation in
LVM among adolescent females. In this context, the objective of the present study was to examine the contribution of CA, skeletal maturity status, training experience and body size descriptors to inter-individual variability of LVM among adolescent female adolescent soccer players using an allometric modelling approach.

\section{Methods}

\section{Procedures}

The research was approved by the Ethics Committee of the University of Coimbra and a signed institutional agreement with the Portuguese Institute of Sports. Participants voluntarily visited the Center for Sports Medicine as part of the required medical examination for registration in the Portuguese Soccer Federation (Law 204/2006; act 11/ 2012). Parents or legal guardians and the players provided written consent; the players were informed that their participation was voluntary and that they could withdraw from the study at any time. During the visit to the medical Center, a radiograph of the left hand-wrist was taken for the purpose of SA estimation, echocardiography was conducted, and a series of anthropometric dimensions were measured. Each of the protocols was conducted by qualified Center personnel in the respective domains.

\section{Participants}

The sample included 228 female soccer players 11.8 17.1 years ( $14.6 \pm 1.1$ years). All players were registered in competitive clubs affiliated with the Portuguese Soccer Federation. Inclusion criteria were engagement in formal training and competition for at least one complete year, Caucasian ethnicity, no symptoms of underlying cardiovascular disease, and no family history of cardiovascularrelated mortality. Training experience was expressed as years of participation in competitive soccer at the club level, including registration with the Portuguese Soccer Federation. Individual information was obtained by interview on the day of observation and confirmed in consultation with institutional records of the Federation.

\section{Chronological age (CA) and maturity status}

CA was calculated as the difference between date of the clinical examination and date of birth. SA was estimated with the Fels method [25], which includes maturity indicators for each of the 22 bones of hand-wrist and ratios of epiphyseal-diaphyseal widths. Grades and measurements for each indicator were entered into the Felshw 1.0 software (Felshw 1.0, Software Lifespan Health and Research Center, Departments of Community Health and Pediatrics, Booshoft School Medicine, Wright State University Dayton Ohio, USA) to derive an estimate of SA and the associated standard error. The same trained observer assessed all radiographs. The maturity status of each individual was subsequently classified [26] as late (SA younger than CA by 
more than 1.0 year), average or on time (the difference between SA and CA was within the band of -1.0 years to + 1.0 years), early (SA older than CA by more than 1.0 years), or mature (SA is not assigned).

\section{Anthropometry}

Body dimensions were measured following standardized procedures [27]. Stature was measured to the nearest $0.1 \mathrm{~cm}$ using a stadiometer (model 98.603, Holtain Limited Crosswell, Crymych, UK) and body mass was measured to the nearest $0.1 \mathrm{~kg}$ using a digital scale (SECA, model 770, Hanover, MD, USA). Skinfold thickness was measured to the nearest $0.5 \mathrm{~mm}$ at two sites, triceps and medial calf using a Lange caliper (Beta Technology Incorporated Cambridge, Maryland, USA). Body fat (fat mass, FM) as a percentage of body mass (\%FM) was estimated from the two skinfolds using Eq. 1 recommended for female adolescents of White/European ancestry [28]. Absolute FM and FFM were derived.

$$
\% \mathrm{FM}=0.610 \mathrm{x}(\text { triceps skinfold }+ \text { medial calf skinfold })+5.1
$$

\section{Echocardiography}

Resting echocardiographs were taken with a Vivid 3 ultrasound machine with a 1.5 to $3.6 \mathrm{MHz}$ transducer (GE Vingmed Ultrasound, Horten, Norway). Two-dimensional images (recorded at $100 \mathrm{~mm} / \mathrm{s}$ ) were used to derive Mmode echocardiograms for direct visualization. Measurements of the internal dimension of the left ventricle at end diastole (LVIDd), septal wall thickness at end diastole (SWTd), and posterior wall thickness at end diastole (PWTd) were made following the procedures of the American Society of Echocardiography. Intra-observer technical errors of measurement and variability based on echocardiograms of 20 randomly selected adolescents measured twice within a one-week interval were previously reported [29]. Technical errors and 95\% confidence levels were: LVIDd, $0.17 \mathrm{~mm}$ (95\% LOA, $1.95-2.28 \mathrm{~mm}$, \%CV = 0.3, 95\% LOA: 4.1-4.8\%); SWTd, $0.02 \mathrm{~mm}$ (95\% LOA, $0.30-0.34 \mathrm{~mm}$, $\% \mathrm{CV}=0.3$, 95\% LOA, 4.2-4.8\%); and PWTd, $0.06 \mathrm{~mm}$ (95\% LOA, $0.45-0.56 \mathrm{~mm}, \% \mathrm{CV}=0.8$, 95\% LOA, 6.58.1\%). LVM was estimated using Eq. 2 [30] and relative wall thickness (RWT) was calculated using Eq. 3 [31]:

$\mathrm{LVM}=0.8 \times\left\{\left(1.04[\mathrm{LVIDd}+\mathrm{PWT}+\mathrm{SWTd})^{3}-(\mathrm{LVIDd})^{3}\right]\right\}+0.6$

RWT $=(2 \times$ PWTd $) /$ LVIDd

\section{Analyses}

Descriptive statistics were calculated and normality of distributions checked. Pearson correlations were used to estimate relationships among CA, SA and training experience in years, on one hand, and body size descriptors (stature, body mass and FFM) and echocardiographic parameters, on the other hand. Pearson correlations were also used to examine associations between the body size descriptors and parameters of LVM (simple and derived variables). Magnitude of the correlation coefficients was interpreted as follows [32]: trivial $(\mathrm{r}<0.10)$, small $(0.10 \leq$ $\mathrm{r}<0.30)$, moderate $(0.30 \leq \mathrm{r}<0.50)$, large $(0.50 \leq \mathrm{r}<$ $0.70)$, very large $(0.70 \leq r<0.90)$ and nearly perfect $(r \geq$ 0.90). Simple allometric models following procedures proposed by Nevill, Ramsbottom and Williams [19] and Nevill and Holder [20] were subsequently applied to the total sample:

$$
y=a \cdot x^{k} \cdot \varepsilon
$$

$$
\ln y=\ln a+k \cdot \ln x+\ln \varepsilon
$$

Equation 5 corresponds to the natural logarithmic transformation of Eq. 4. It permitted the determination of the constant and power function for each size descriptor. In both equations, $y$ corresponded to LVM, while $a$ and $k$ were, respectively, the constant and scaling exponents. Simple allometric models were validated by the inspection of the correlations between scaled LVM and the respective independent variables (size descriptors). The influence of size descriptors was removed when the coefficients of correlation approached zero. Finally, multiplicative allometric models were derived by combining size descriptors (stature, body mass, FFM), $\mathrm{CA}$, years of training and skeletal maturity status (coded as dummy variables; the 65 skeletally mature participants were not considered in the simple and multiplicative allometric models). Backward stepwise multiple regression with $p<0.10$ as the criteria for removal was used to develop a parsimonious model. This procedure reduces collinearity among independent variables. Diagnostic statistics to evaluate the proportion of variability in an independent variable that was not explained by the other independent variables (tolerance) were used to examine multicollinearity for the final models. The variance inflation factor (VIF) was also calculated. Variables were retained if tolerance was $\geq 0.1$ and VIF was $>10$ (to an $\mathrm{R}^{2}$ of 0.90). For each allometric model, the coefficient of determination $\left(\mathrm{R}^{2}\right)$ was calculated to estimate the explained variance. 
$\ln (\mathrm{LVM})=k_{1} \cdot \ln ($ stature in $\mathrm{cm})$

$+k_{2}$. $\ln$ (body mass in $\mathrm{kg}$ )

$+k_{3}$. $\ln (\mathrm{FFM}$ in $\mathrm{kg})+a+b_{1}$. (CA in years $)$

$+b_{2}$. (training experience in years) $+b_{3}$.

(maturity status : late vs average;

late vs early maturing, with late maturing being zero) $+\ln \varepsilon$

Differences between skeletal maturity groups in size descriptors (stature, body mass, FFM) and in absolute and scaled values of LVM were graphically compared. The magnitude of mean differences between maturity groups was interpreted using Cohen's $d$ value as follows [32]: $<0.20$ (trivial), 0.20-0.59 (small), 0.60-1.19 (moderate), 1.20-1.99 (large), 2.00-3.99 (very large), > 4.00 nearly perfect.

Statistical analyses were done with SPSS version 20.0 (SPSS Inc., IBM Company, N.Y., USA) and Graphpad Prism (version 5.00 for Windows, GraphPad Software, San Diego California USA, www.graphpad.com). Alpha level was set at 0.05 .

\section{Results}

Descriptive statistics for training experience, CA, SA, stature, body mass, BSA, body composition and echocardiographic parameters are summarized in Table 1. The distribution of players by maturity status (SA minus CA) was also indicated. CA was significantly correlated with stature $(\mathrm{r}=0.19, p<0.05)$, BSA $(\mathrm{r}=0.21, p<0.01)$, body mass $(\mathrm{r}=0.18, p<0.05)$, FFM $(\mathrm{r}=0.21, p<0.01)$ and LVM $(r=0.13, p<0.05)$, but the correlations were low. Mean SA was advanced, on average, by approximately 0.65 year, relative to mean CA. SA was moderately correlated with FFM $(\mathrm{r}=0.39, p<0.01)$, BSA $(\mathrm{r}=0.41, p<$ $0.01)$ and body mass $(r=0.41, p<0.01)$. Correlations between training experience and several variables were lower but significant: negative with \%FM $(\mathrm{r}=-0.15, p<$ $0.05)$; positive for cardiac variables: ISWTd $(\mathrm{r}=0.28, p<$ $0.01)$, PWTd $(\mathrm{r}=0.25, p<0.01)$, LVM $(\mathrm{r}=0.22, p<0.01)$ and the LVM index $(r=0.29, p<0.01)$. Means for LVIDd, ISWTd and PWTd were $43.5 \mathrm{~mm}, 7.6 \mathrm{~mm}$ and $7.5 \mathrm{~mm}$, respectively, in the skeletally mature players.

Correlations between size descriptors and dependent variables varied from moderate to large (Fig. 1a-c).

Table 1 Descriptive statistics and correlations between chronovariables, size and echocardiograph parameters $(n=228)$

\begin{tabular}{|c|c|c|c|c|c|c|c|c|c|c|c|c|c|c|}
\hline \multirow[t]{3}{*}{ Variable } & \multirow[t]{3}{*}{ unit } & \multicolumn{5}{|c|}{ descriptive statistics } & \multirow{2}{*}{\multicolumn{2}{|c|}{$\begin{array}{l}\text { normality } \\
\text { (Kolmogorov- } \\
\text { Smirnov) }\end{array}$}} & \multicolumn{6}{|c|}{ correlations } \\
\hline & & \multirow{2}{*}{$\begin{array}{l}\text { range (min; } \\
\text { max) }\end{array}$} & \multicolumn{2}{|l|}{ mean } & \multirow{2}{*}{$\begin{array}{l}\text { standard } \\
\text { deviation }\end{array}$} & \multirow[t]{2}{*}{ f } & & & \multicolumn{2}{|l|}{$C A$} & \multicolumn{2}{|l|}{ SA } & \multicolumn{2}{|c|}{ training experience } \\
\hline & & & value & $(95 \% \mathrm{Cl})$ & & & value & $p$ & $r$ & $p$ & $r$ & $\mathrm{p}$ & $r$ & $p$ \\
\hline Training experience & years & $(2 ; 9)$ & 5.3 & (5.0 to 5.5$)$ & 2.1 & & 0.149 & $<0.01$ & & & & & & \\
\hline Chronological age & years & $(11.84 ; 17.05)$ & 14.63 & (14.49 to 14.77 ) & 1.11 & & 0.076 & $<0.01$ & & & & & & \\
\hline Skeletal age ${ }^{a}$ & years & $(11.46 ; 17.92)$ & 15.28 & (15.04 to 15.53$)$ & 1.54 & & 0.067 & 0.07 & & & & & & \\
\hline \multicolumn{15}{|l|}{ Skeletal maturity: } \\
\hline delayed & $f$ & & & & & 25 & & & & & & & & \\
\hline average & $f$ & & & & & 51 & & & & & & & & \\
\hline advanced & $f$ & & & & & 87 & & & & & & & & \\
\hline mature & $f$ & & & & & 65 & & & & & & & & \\
\hline Stature & $\mathrm{cm}$ & $(136.0 ; 182.2)$ & 161.3 & (160.4 to 162.2 ) & 6.8 & & 0.056 & 0.08 & 0.192 & $<0.05$ & 0.241 & $<0.01$ & & \\
\hline Body surface area & $m^{2}$ & $(1.07 ; 2.05)$ & 1.59 & (1.57 to 1.61$)$ & 0.2 & & 0.057 & 0.07 & 0.209 & $<0.01$ & 0.413 & $<0.01$ & & \\
\hline Body mass & $\mathrm{kg}$ & $(29.5 ; 101.0)$ & 56.7 & (55.2 to 58.1$)$ & 11.0 & & 0.090 & $<0.01$ & 0.176 & $<0.01$ & 0.405 & $<0.01$ & & \\
\hline \multirow[t]{2}{*}{ Fat mass } & $\%$ & $(7.5 ; 51.6)$ & 25.4 & (24.4 to 26.4 ) & 7.7 & & 0.075 & $<0.01$ & & & 0.230 & $<0.01$ & -0.148 & $<0.05$ \\
\hline & kg & $(3.3 ; 51.4)$ & 15.0 & (14.0 to 16.0 ) & 7.5 & & 0.165 & $<0.01$ & & & 0.292 & $<0.01$ & & \\
\hline Fat-free mass & $\mathrm{kg}$ & $(26.2 ; 62.5)$ & 41.7 & (40.9 to 42.5 ) & 5.8 & & 0.051 & 0.20 & 0.213 & $<0.01$ & 0.391 & $<0.01$ & & \\
\hline LVIDd & $\mathrm{mm}$ & $(28.9 ; 56.1)$ & 45.2 & (44.7 to 45.7 ) & 3.6 & & 0.077 & $<0.01$ & & & 0.242 & $<0.01$ & & \\
\hline ISWTd & $\mathrm{mm}$ & $(5.4 ; 10.2)$ & 7.7 & (7.6 to 7.8 ) & 0.9 & & 0.064 & 0.03 & & & 0.203 & $<0.01$ & 0.288 & $<0.01$ \\
\hline PWTd & $\mathrm{mm}$ & $(5.0 ; 9.6)$ & 7.5 & (7.4 to 7.6 ) & 0.8 & & 0.097 & $<0.01$ & & & & & 0.249 & $<0.01$ \\
\hline LVM & g & $(50 ; 185)$ & 107 & (104 to 110$)$ & 22 & & 0.049 & 0.20 & 0.131 & $<0.05$ & 0.274 & $<0.01$ & 0.222 & $<0.01$ \\
\hline LVM index & g.m ${ }^{-2}$ & $(33 ; 107)$ & 67 & (66 to 69 ) & 11 & & 0.023 & 0.20 & & & & & 0.286 & $<0.01$ \\
\hline
\end{tabular}

CA Chronological age, SA Skeletal age, $f$ frequency, LVIDd Left ventricular internal dimension at end of the diastole, ISWTd Interventricular septal wall thickness at end of the diastole, PWTd Posterior wall thickness at end of the diastole, LVM Left ventricular mass, LV index Left ventricular mass index = LVM / body surface area, $f$ Absolute frequency, $95 \% \mathrm{Cl}$ (95\% confidence intervals)

${ }^{a} n=163$; players classified as skeletally mature $(n=65)$ were not considered in the analysis 

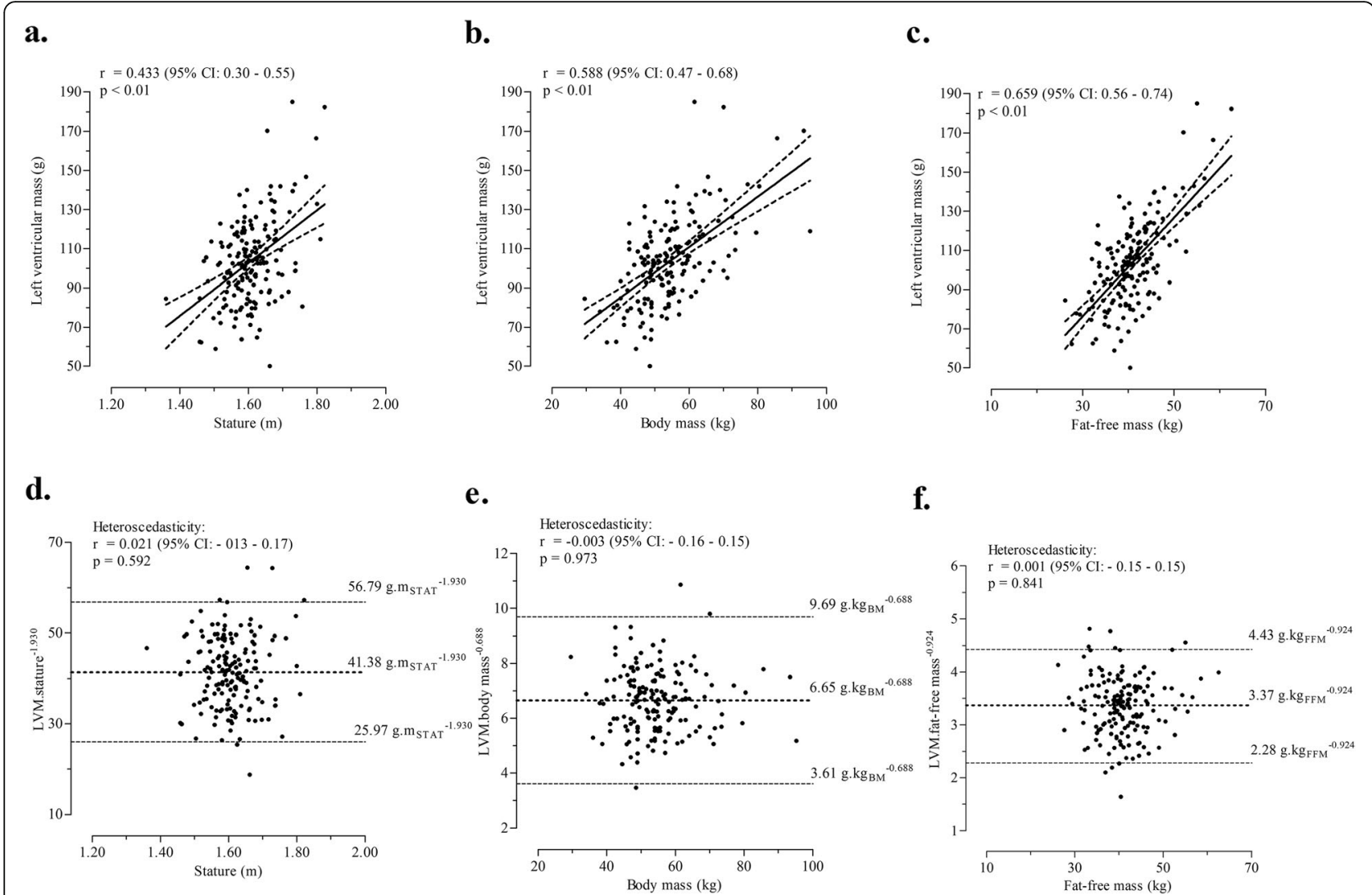

Fig. 1 Relationship of LVM to stature (a), body mass (b) and fat-free mass (c), and correlations between power functions and respective size descriptors (d, e and $\mathbf{f}$ )

Accordingly, simple allometric models between logarithmic transformations were calculated using stature, body mass and FFM as size descriptors to obtain dimensionless models aimed to explain inter-individual variability of LVM (Table 2). The allometric coefficients explained 16 to $37 \%$ of variance in LVM showing a linear relationship between LVM and FFM ( $\mathrm{k}=0.924,95 \% \mathrm{CI}$ : 0.737 to 1.112). Power function exponents for stature $(k=1.930$, 95\%CI: 1.240 to 2.620$)$ and body mass $(k=0.688,95 \% \mathrm{CI}$ : 0.536 to 0.840 ) were, respectively, above and below, the unit corresponding to linearity. Finally, correlations between scaled variables and LVM were negligible for all size descriptors, suggesting that the simple allometric models were effective to evaluate LVM independent of body size (Fig. 1d-f).

The panels of Fig. 2 illustrate maturity-associated variation in stature, body mass, FFM and LVM. LVM showed the same maturity gradient (i.e. late $<$ average $<$ early) as noted for size descriptors. Comparisons of late and average maturing groups indicated consistently moderate Cohen's d values $(0.85<\mathrm{d}<1.04)$. Corresponding comparisons between late and early maturing indicated magnitude differences ranging from moderate $(\mathrm{d}=$ 0.82 for stature; $\mathrm{d}=1.12$ for body mass) to large $(\mathrm{d}=$
1.30 for FFM). Finally, differences between average and early maturing players tended to be trivial (stature: $\mathrm{d}<$ 0.20 ) or small (body mass: $\mathrm{d}=0.46$; FFM: $\mathrm{d}=0.36$ ).

Taking into account interrelationships among size descriptors and skeletal maturity status, it was decided to examine their multiplicative effects on heart size. Table 3 summarizes the results of multiplicative allometric modelling combining size descriptors, CA and training experience with maturity status as a dummy variable. The explained variance for LVM increased to $46 \%$; the resulting equation was as follows:

$$
\begin{aligned}
\ln (\mathrm{LVM})= & 1.070+0.412 \times \ln (\text { body mass }) \\
+ & 0.621 \times \ln (\mathrm{FFM})-0.028 \times(\mathrm{CA}) \\
+ & 0.022 \times(\text { training experience })+0 \\
& (\text { if maturity status }=\text { late }) \\
& -0.137 \text { (if maturity status = average }), \\
& \text { and }-0.116 \text { (if maturity status }=\text { early }) .
\end{aligned}
$$

When using scaled LVM values, the maturity-associated gradient was attenuated, and adolescent female soccer 
Table 2 Bivariate correlations and simple allometric models between LVM and size descriptors $(n=163)$

\begin{tabular}{|c|c|c|c|c|c|c|c|c|c|c|}
\hline \multirow[t]{3}{*}{$\begin{array}{l}\mathrm{X}_{\mathrm{i}} \text { : size } \\
\text { descriptors }\end{array}$} & \multicolumn{3}{|c|}{ correlations between LVM and size $X_{i}$} & \multicolumn{6}{|c|}{$\begin{array}{l}\text { simple alometric models } \\
{\left[\ln (\mathrm{LVM})=\ln (\mathrm{a})+k_{i} \times \ln \left(\mathrm{X}_{\mathrm{i}}\right)+\log (\varepsilon)\right]}\end{array}$} & \multirow[t]{3}{*}{ correlation $\left(X_{i}, L V M / X_{i}^{k}\right)$} \\
\hline & \multirow[t]{2}{*}{ r } & \multirow[t]{2}{*}{$95 \% \mathrm{Cl}$} & \multirow[t]{2}{*}{ (qualitative) } & \multirow[t]{2}{*}{ a } & \multicolumn{2}{|l|}{$k_{i}$} & \multicolumn{3}{|c|}{ model summary } & \\
\hline & & & & & value & $(95 \% \mathrm{Cl})$ & $\mathrm{R}$ & $R^{2}$ & $p$ & \\
\hline Stature & 0.433 & (0.299 to 0.550$)$ & (moderate) & -5.185 & 1.930 & (1.240 to 2.620$)$ & 0.399 & 0.159 & $<0.01$ & 0.021 \\
\hline Body mass & 0.588 & (0.477 to 0.680$)$ & (large) & 1.878 & 0.688 & (0.536 to 0.840$)$ & 0.576 & 0.332 & $<0.01$ & -0.003 \\
\hline Fat-free mass & 0.659 & (0.562 to 0.738$)$ & (large) & 1.199 & 0.924 & (0.737 to 1.112$)$ & 0.608 & 0.366 & $<0.01$ & 0.001 \\
\hline
\end{tabular}

LVM Left ventricular mass, $r$ correlation coefficient, $95 \% \mathrm{Cl} 95 \%$ confidence intervals, $k_{i}$ scaling coefficient, $\varepsilon$ error, $a$ constant, $R^{2}$ Explained variance

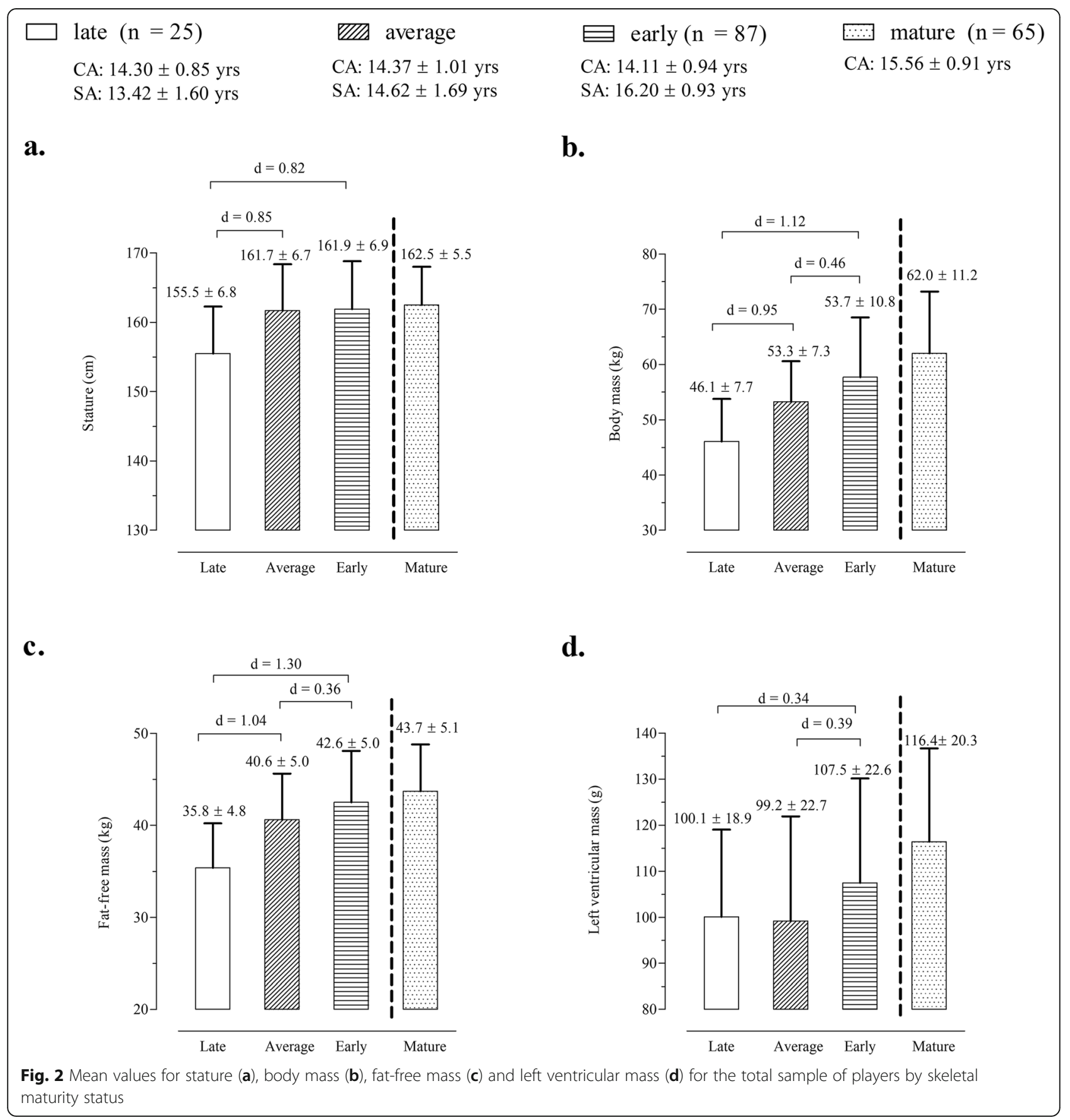


Table 3 Multiplicative allometric modelling* of LVM combining size, CA, skeletal maturation and training $(n=163)$

\begin{tabular}{|c|c|c|c|c|c|c|c|c|c|}
\hline \multirow[t]{2}{*}{ Predictors } & \multirow[t]{2}{*}{ constant } & \multirow[t]{2}{*}{ coefficients } & \multirow[t]{2}{*}{$p$} & \multicolumn{2}{|l|}{ collinearity } & \multicolumn{4}{|c|}{ model summary $^{a}$} \\
\hline & & & & tolerance & VIF & $\bar{R}$ & $\mathrm{R}^{2}$ adjusted & $\mathrm{F}$ & $p$ \\
\hline & & & & & & 0.694 & 0.462 & 24.146 & $<0.01$ \\
\hline & 1.070 & & $<0.01$ & & & & & & \\
\hline In (body mass) & & 0.412 & $<0.01$ & 0.307 & 3.259 & & & & \\
\hline In (fat-free mass) & & 0.621 & $<0.01$ & 0.288 & 3.470 & & & & \\
\hline Chronological age & & -0.028 & 0.05 & 0.845 & 1.184 & & & & \\
\hline Training experience & & 0.022 & $<0.01$ & 0.777 & 1.287 & & & & \\
\hline \multicolumn{10}{|c|}{ Skeletal maturity status } \\
\hline Late vs average & & -0.137 & $<0.01$ & 0.397 & 2.520 & & & & \\
\hline Late vs early & & -0.116 & $<0.01$ & 0.339 & 2.952 & & & & \\
\hline
\end{tabular}

VIF Variance inflation factor, $R^{2}$ Explained variance

${ }^{\mathrm{a}}$ In $(\mathrm{LVM})=k_{1} \times \ln$ (stature) $+k_{2} \times \ln$ (body mass) $+k_{3} \times \ln$ (fat-free mass) $+\mathrm{a}+b_{1} \times(\mathrm{CA})+b_{2} \times$ (training years) $+b_{3} \times($ maturity status: late vs average; late vs early maturing, with late maturing being zero) $+\ln \varepsilon$

players classified as delayed (late maturing group) showed similar values compared to other maturity groups (Fig. 3).

\section{Discussion}

The contributions of CA, skeletal maturity status, training experience in competitive soccer and indicators of body size to inter-individual variability in LVM was considered among Portuguese adolescent female soccer players 11.8-17.1 years of age. The predicted variable (i.e., LVM) was interpreted as tri-dimensional and, not surprisingly, the contribution of the stature (uni-dimensional size descriptor) to the explained variance in LVM was relatively low (about 16\%). Stature did not consistently enter the final multiplicative allometric model. On the other hand, FFM (tri-dimensional indicator) was the best single predictor of LVM, explaining $37 \%$ of the variance. Its scaling coefficient, $k=0.924$ (95\%CI: 0.737 to 1.112), suggested a linear relationship with LVM (geometric similarity). Body mass, another tri-dimensional indicator, had a scaling coefficient, $k=0.688$ (95\%CI: 0.536 to 0.840$)$, that departed from linearity and suggested an elastic relationship between body mass and LVM. The final multiplicative allometric model suggested that body mass, FFM and training experience in soccer were directly associated with LVM, and after controlling for the preceding, average and early maturing players had a proportionally smaller LVM compared to late maturing peers (reference group in the analysis).

The adolescent female soccer players had a mean stature at the 50th percentile of the US reference data for girls of the same age [33], but a mean body mass between the 50th and 75th percentiles of the reference. The tendency for greater mass-for-stature may reflect their advanced skeletal maturity status, consistent with cross-sectional observations for Portuguese adolescent male soccer players [34-37]. The body mass index (BMI) each individual participant was also plotted relative to US age-specificz-scores [33] and the majority of female soccer players $(n=194)$ ranged between -1.0 and +1.0 , while 26 players had BMIs that exceeded + 1.0. In addition, 103 of the soccer players were characterized by an excessive amount of fatness predicted from two skinfolds ( $>25 \%)$, and the data showed a maturityrelated gradient in \%FM: early>average $>$ late. It is thus possible that excess body mass-for-stature may reflect increased FM. Nevertheless, future studies should consider alternative assessments of body composition such dual-energyx-ray absorptiometry (DEXA) or air displacement plethysmography, may provide more accurate estimates of FM and FFM.

Absolute values for LVM, LVIDd and PWTd in the current study were comparable to those reported for 32 American female soccer players 13-18 years [38]. Interpretation and comparison of cardiac indicators across samples are influenced by body size and composition, but detailed information on the body dimensions of the American sample was not reported. Additionally, a slight increase in LV cavity and lower PWT were noted in the present sample of soccer players compared to female swimmers of the same age and similar average body masses [39]. It is possible that the results suggest eccentric remodelling independent of physiological adaptations to the haemodynamic loading associated with soccer participation [13, 31, 40, 41].

Theoretical allometric coefficients of $k=2.13$ and $k=$ 2.65 for stature have been adopted to normalize the effects of body size in LVM $[6,7,14,31,42]$. The simple allometric models in the current study, however, noted a lower exponent for stature $(k=1.930)$. The differences may reflect sampling variation, methodological constraints, statistical procedures, sex and/or age-associated variation. Moreover, stature only explained $\approx 16 \%$ of the variance in LVM and was not included in the proportional allometric model. Overall, the findings suggested 


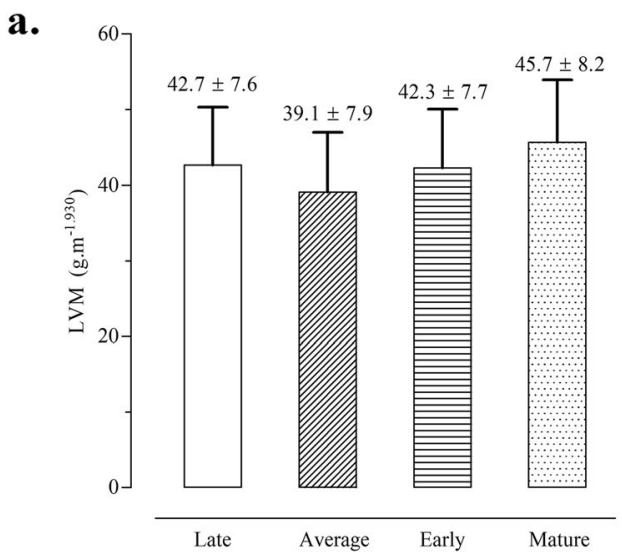

b.

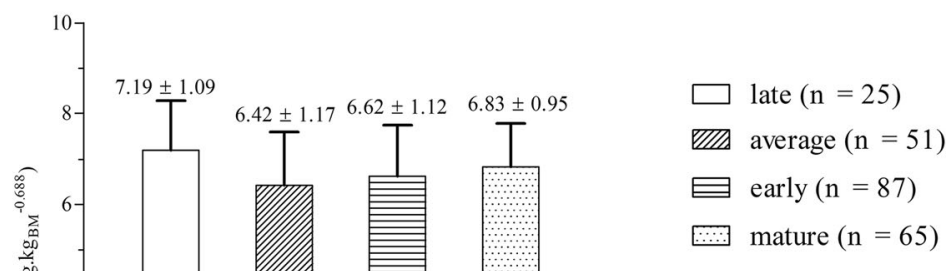

c.

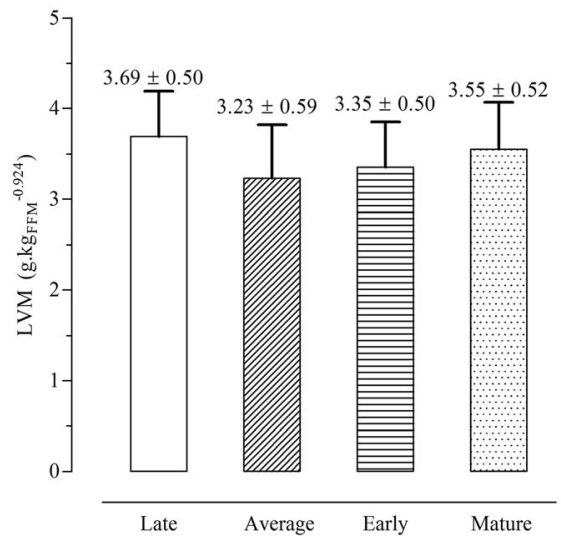

Fig. 3 Means and standard deviations by skeletal maturity groups for scaled LVM expressed per unit of stature (a), body mass (b) and fat-free mass (c)

that stature alone should not be considered to normalize or predict LVM. Similar results were also noted in 464 highly trained junior male and female athletes 14-18 years participating in cycling, soccer (males only), rowing, swimming and tennis, with small numbers in other sports [5].

It is possible that other size descriptors may be needed to normalize LVM. More recently, FFM based on DEXA was noted as the best size descriptor to compare LVM in 75 young adult females in static or dynamic sport activities [15]. Among dependent variables in the current study, FFM was the best explanatory predictor of LVM, confirming the influence of metabolically active tissues on cardiac output. Results of the present study also suggested a linear relationship between the logarithmic transformations of LVM and FFM. The utility of simple 
ratios to estimate cardiac output of LVM per unit of FFM was noted in studies of trained [13] and untrained adults [43] consistent with the theoretical range of geometric similarity, i.e., LVM is represented as a cubic expression and as such requires a 3-dimenisonal variable for normalization. On the other hand, the interpretation of LVM considering only FFM is limited by a lack of comparative studies in youth female sport participants.

Multiplicative allometric models are physiologically plausible and accommodate heteroscedasticity in the distribution of a variable, and thus provide a better statistical fit than simple models [44]. Not surprisingly, FFM combined with years of training in soccer and biological maturity status provided a better understanding of LVM than simple allometric models. The results were consistent with previous cross-sectional studies of adolescent sport [16] and non-sport participants [45] in showing that the interrelationships between growth and maturation are determinants of LVM. However, the contribution of SA per se was not a significant predictor of LVM in Portuguese male roller hockey players 14.5-16.5 years of age [16]. In contrast, results of the multiple backward regression analysis among adolescent female soccer players indicated that maturity status defined by SA minus CA was a significant determinant of LVM. SA provided perhaps the most accurate estimate of maturity status, i.e., the state of maturation of the hand-wrist bones at the time of observation [1]. By inference, SA should be expressed relative to CA for inclusion in multiplicative allometric models.

A gradient of maturity associated differences in size and LVM were noted in the soccer players (early $>$ on time $>$ late maturing girls). Early maturing players tended to be heavier and relatively fatter and presented a larger LVM compared to average and late maturing players (Fig. 2). This was consistent with observations for 6029 Flemish girls $6-16$ years of age which showed a positive relationship between fatness and SA based on the Tanner-Whitehouse 2 method [46]. The trends thus suggested that absolute values of LVM were significantly influenced by early maturation which in turn was related to body composition, specifically pubertal gains in FM. Although FM does not have a strong relationship with LVM, sports participation was associated with changes in FM and FFM [22] which may be a potential explanation for the inclusion of years of training in soccer and FFM in the final allometric model. Nevertheless, the multiplicative allometric model indicated that differences in LVM among maturity groups were reversed when body mass, FFM, CA and training experience were appropriately controlled. After controlling for body size descriptors (i.e., scaled LVM output), there were no substantial differences amongst female adolescent soccer players contrasting in maturity status (Cohen's d values were less than 0.20 as showed in Fig. 3a-c). A study of peak oxygen uptake among 54 adolescent females (10.713.5 years) to evaluate allometric models for concurrent size descriptors (stature, body mass and FFM) noted that scaled performance did not differ according to categories of self-assessed pubic hair development [47]. Among 59 male adolescent basketball players, those aged 14 years and classified in stage 3 for clinically assessed pubic hair development (mid-puberty) performed, on average, better on the 20-m shuttle run test than peers of the same age classified in stage 5 (post-pubertal) [48]. Overall, the available studies show that early maturing adolescents tend to be taller, heavier and stronger, but may not demonstrate superior performance in aerobic fitness tests.

Generally comparable results showing an influence of predicted maturity status based on predicted maturity offset, i.e., time before or after PHV on absolute values of peak force were noted in a cross-sectional study of 157 female soccer players combined across four competitive age groups, U10 through U16 [49]. However, conclusions based on predicted maturity offset as an indicator of maturity status across this broad age range should be interpreted with caution given limitations of the equation used to predict maturity offset in girls. More specifically, predicted offset and in turn predicted age at PHV are affected by CA at prediction and has major limitations in early and late maturing girls defined by observed ages at PHV in two validation studies based on longitudinal samples $[50,51]$.

The distinction between physiologic increases in LVWT in athletes (i.e., athlete's heart) and hypertrophic cardiomyopathy accounts for about one-third of all exercise-related sudden cardiac deaths in trained athletes aged < 35 years old [52-54], and intense competitive sport is not recommended [55]. To define physiologic limits of left ventricular hypertrophy in elite adolescent athletes, echocardiography was performed among 720 elite adolescent athletes (75\% male) aged 14-18 years participating in ball, racket, and endurance sports, and in 250 healthy sedentary controls of similar age, sex, and body surface area [56]. Only a small proportion of athletes exhibited a LVWT exceeding upper limits and authors concluded that compared with controls, adolescent athletes had greater absolute LVWT. However, it should be noted that many sports tend to recruit/select and promote young athletes that have larger body sizes [23, $35,48]$ and interpretation of both wall thickness and cavity diameter should be done according to principles of geometric similarity of heart size to body size [19]. LVM is a tri-dimensional variable and, consequently, it is not expected to have a linear relationship with stature in $\mathrm{cm}$. Linearity is, however, expected between LVM and FFM which is the metabolically active component of body mass. Athletes exposed to systematic training tend 
to be characterized by a larger FFM [1, 22]. Identification of athletes exceeding physiological limits is thus recommended. In addition, skeletal maturity status is an additional source of inter-individual variation in LVM, but does not correspond to any abnormality when LVM is scaled properly.

Although the present study considers a previously under studied population (adolescent female soccer players) and includes of a valid and established indicator of maturity status, specifically SA, several limitations of the present study should be noted. The sex-specific equation for predicting \%FM from two-skinfold thicknesses has a standard error of estimate of 3.8\% [28]. FM was estimated as predicted \%FM $\times$ body mass, and FMM was derived by subtraction (body mass - FM =FFM). Based on the two skinfolds used in the present study, \%FM was $18.6 \pm 7.2 \%$ in a combined sample 126 youth soccer players (mean age: 13.3 years, 86 boys, 40 girls) and was lower than estimated \%FM based on DEXA, $21.9 \pm 5.8 \%$ [57]. Unfortunately, the prediction equations are different for boys and girls so that comparisons with the combined sample should be interpreted with caution. The equation for boys [28] was also used in adolescent roller hockey players [16]; estimates of FM and FFM derived from predicted \%FM were significant contributors to inter-individual variability in LVM using allometry (FM: $r=0.56,31 \%$ explained variance; FFM: $r=$ $0.51,26 \%$ explained variance).

Future research is needed to examine intra- and interindividual variability in LVM associated with specific aspects of sport training and participation and internal and external markers of training load such as minutes and sessions, and ratings of perceived exertion. Moreover, characteristics of training process are generally specific for initiates, juveniles or juniors (competitive age groups by the Portuguese Soccer Federation). Although the sample size in the present study $(n=163)$ was larger than in previous studies, the cross-sectional design does not support a cause-effect relationship between size descriptors and cardiac remodeling. Finally, although echocardiography is still the most widely used method for assessing LVM, cardiac magnetic resonance imaging is considered the gold standard for determining LVM.

\section{Conclusions}

Results of this cross-sectional study of adolescent female soccer players indicated that inter-individual variance in LVM is, in part, explained by skeletal maturity status which affects body size and composition. Specifically, a larger body size tended to be associated with early maturing participants. Skeletal maturation, training experience, body size and composition should be considered in the interpretation of an athlete's heart. The study also highlighted the utility of multiplicative allometric models for understanding LVM among adolescent girls participating in competitive soccer. Interpretation of echocardiography data from adolescent athletes apparently exceeding the physiologic limits of left ventricular size may require the assessment of body composition and SA.

\section{Abbreviations}

LVM: Left ventricular mass; BSA: Body surface area; FFM: Fat-free mass; FM: Fat mass; \%FM: Percentage of fat mass; CA: Chronological age; SA: Skeletal age; PHV: Peak height velocity; LVIDd: Internal diameter of left ventricle at end diastole; SWTd: Septal wall thickness at end diastole; PWTd: Posterior wall thickness at end diastole; LWWT: Left ventricular wall thickness; RWT: Relative wall thickness; DEXA: Dual-energy $x$-ray absorptiometry; BMl: Body mass index

\section{Acknowledgments}

We are grateful to the Portuguese Institute of Sports and Youth [IPDJ/ FCDEF.UC/2017-01].

\section{Authors' contributions}

Conceived and design the experiments: MJCS, JMC. Performed the experiments: DVM, MJCS, AOG, JGS. Analyzed the data: DVM, JVS, MJCS, JPD, PLF, LBS, RMM. Data interpretation: DVM, JVS, MJCS, PLF, JPD, LBS, RMM. Wrote the paper: DVM, JVS, MJCS, LGOL, DRLM, NL, SPC, LBS, RMM. Revised the manuscript content: DVM, JVS, MJCS, AOG, JPD, PLF, LGOL, DRLM, NL, JC, $J M C, S P C, L B S, R M M$. Approved the final version of manuscript: DVM, JVS, MJCS, AOG, JPD, PLF, JGS, LGOL, DRLM, NL, JC, JMC, SPC, LBS, RMM.

\section{Funding}

Diogo V. Martinho, Joao Valente-dos-Santos, Manuel J. Coelho-e-Silva, Arturo O. Gutierrez, João P. Duarte, Leonardo G. O. Luz and Joaquim M. Castanheira are members of CIDAF [uid/dtp/04213/2020] that is supported by the Portuguese Foundation for Science and Technology. Diogo V. Martinho (SFRH/BD/ 121441/2016) and Joao Valente-dos-Santos (SFRH/BPD/100470/2014) were granted by the Portuguese Foundation for Science and Technology. Arturo O. Gutierrez performed a PhD Grant from the Mexican Government [Secretaria de Educação Publica]. No other current funding sources for this study. The Portuguese Foundation for Science and Technology. the Mexican Government played no role in the design, collection, analysis or interpretation of the data, nor in the preparation of the manuscript or decision to submit the manuscript for publication.

\section{Availability of data and materials}

The database supporting the conclusions of this article is available from the corresponding author on reasonable request.

\section{Ethics approval and consent to participate}

The research was approved by the Ethics Committee of the University of Coimbra [CE/FCDEF-UC/00122014]. A signed inter-institutional agreement was performed with the Portuguese Institute of Sports and Youth [IPDJ/ FCDEF.UC/2017-01]. Participants voluntarily visited the Center for Sports Medicine as part of the required medical examination for registration in the Portuguese Soccer Federation (Law 204/2006; act 11/2012). Parents or legal guardians and the players provided written consent; the players were advised that their participation was voluntary and that they could withdraw from the study at any time.

Consent for publication

Not applicable.

\section{Competing interests}

JVS is an editorial board member of BMC Pediatrics. All other authors declare that they do not have any competing interest.

\section{Author details}

${ }^{1}$ Faculty of Sport Sciences and Physical Education, University of Coimbra, Coimbra, Portugal. ${ }^{2}$ CIDAF (uid/dtp/04213/2020), University of Coimbra, Estadio Universitario, Pavilhao III, Coimbra, Portugal. ${ }^{3}$ Faculty of Physical Education and Sport, Lusófona University, Lisbon, Portugal. ${ }^{4}$ Sonora Institute 
of Technology, Sonora, Mexico. ${ }^{5}$ LACAPS, Federal University of Alagoas, Arapiraca, Brazil. 'Sports Medicine Centre, Portuguese Institute of Sports and Youth, Porto, Portugal. ${ }^{7}$ School of Physical Education and Sport of Ribeirão Preto, University of São Paulo, Ribeirao Preto, Brazil. ${ }^{8}$ Physical Education Department, Research Nucleus of Quality of Life, Federal University of Parana, Curitiba, Parana, Brazil. ${ }^{9}$ Department of Clinical Physiology, School of Health and Technology, Polytechnic Institute of Coimbra, Coimbra, Portugal.

${ }^{10}$ Department for Health, University of Bath, Bath, UK. ${ }^{11}$ School of Sport, Exercise and Health Sciences, Loughborough University, Loughborough, UK. ${ }^{12}$ Department of Kinesiology and Health Education, University of Texas, Austin, USA. ${ }^{13}$ School of Public Health and Information Sciences, University of Louisville, Louisville, KY, USA.

Received: 9 August 2019 Accepted: 24 March 2020

Published online: 13 April 2020

\section{References}

1. Malina RM, Bouchard C, Bar-Or O. Growth, maturation, and physical activity. Human Kinetics: Champaign; 2004.

2. Janz KF, Dawson JD, Mahoney LT. Predicting heart growth during puberty: the Muscatine study. Pediatrics. 2000;105:63.

3. Dekkers C, Treiber FA, Kapuku G, Van Den Oord EJCG, Snieder H. Growth of left ventricular mass in African American and European American youth. Hypertension. 2002;39:943-51.

4. Sabo RT, Yen MS, Daniels S, Sun SS. Associations between childhood body size, composition, blood pressure and adult cardiac structure: the Fels Longitudinal Study. PLoS One. 2014. https://doi.org/10.1371/journal.pone. 0106333.

5. George K, Sharma S, Batterham A, Whyte G, McKenna W. Allometric analysis of the association between cardiac dimensions and body size variables in 464 junior athletes. Clin Sci (Lond). 2001;100:47-54.

6. Dewey FE, Rosenthal D, Murphy DJ, Froelicher VF, Ashley EA. Does size matter? Clinical applications of scaling cardiac size and function for body size. Circulation. 2008;117:2279-87.

7. Pressler A, Haller B, Scherr J, Heitkamp D, Esefeld K, Boscheri A, et al. Association of body composition and left ventricular dimensions in elite athletes. Eur J Prev Cardiol. 2012;19:1194-204.

8. Fagard RH. Athlete's heart: a meta-analysis of the echocardiographic experience. Int J Sports Med. 1996;17(Suppl 3):140-4.

9. Scharhag J, Schneider G, Urhausen A, Rochette V, Kramann B, Kindermann W. Athlete's heart: right and left ventricular mass and function in male endurance athletes and untrained individuals determined by magnetic resonance imaging. J Am Coll Cardiol. 2002;40:1856-63.

10. Haykowsky MJ, Samuel TJ, Nelson MD, La Gerche A. Athlete's heart: is the Morganroth hypothesis obsolete? Heart Lung Circ. 2018;27:1037-41.

11. Demirelli S, Sam CT, Ermis E, Degirmenci H, Sen I, Arisoy A, et al. Long-term cardiac remodeling in elite athletes: assessment by tissue Doppler and speckle tracking echocardiography. Echocardiography. 2015;32:1367-73.

12. Golbidi S, Laher I. Exercise and the cardiovascular system. Cardiol Res Pract. 2012. https://doi.org/10.1155/2012/210852.

13. George KP, Birch KM, Pennell DJ, Myerson SG. Magnetic-resonance-imagingderived indices for the normalization of left ventricular morphology by body size. Magn Reson Imaging. 2009;27:207-13.

14. Giraldeau G, Kobayashi Y, Finocchiaro G, Wheeler M, Perez M, Kuznetsova T, et al. Gender differences in ventricular remodeling and function in college athletes, insights from lean body mass scaling and deformation imaging. Am J Cardiol. 2015;116:1610-6.

15. Kooreman Z, Giraldeau G, Finocchiaro G, Kobayashi Y, Wheeler M, Perez M, et al. Athletic remodeling in female college athletes, the "Morganroth hypothesis" revisited. Clin J Sport Med. 2018;29:224-31.

16. Valente-Dos-Santos J, Coelho-e-Silva MJ, Vaz V, Figueiredo AJ, Castanheira J, Leite $\mathrm{N}$, et al. Ventricular mass in relation to body size, composition, and skeletal age in adolescent athletes. Clin J Sport Med. 2013;23:293-9.

17. Dai S, Harrist RB, Rosenthal GL, Labarthe DR. Effects of body size and body fatness on left ventricular mass in children and adolescents: project HeartBeat! Am J Prev Med. 2009:37(Suppl 1):97-104.

18. Chinali M, de Simone G, Roman MJ, Lee ET, Best LG, Howard BV, et al. Impact of obesity on cardiac geometry and function in a population of adolescents: the strong heart study. J Am Coll Cardiol. 2006;47:2267-73.
19. Nevill AM, Ramsbottom R, Williams C. Scaling physiological measurements for individuals of different body size. Eur J Appl Physiol Occup Physiol. 1992 65:110-7.

20. Nevill AM, Holder RL. Modelling maximum oxygen uptake-a case-study in non-linear regression model formulation and comparison. J R Stat Soc Ser C Appl Stat. 1994:43:653-66.

21. de Simone G, Daniels SR, Devereux RB, Meyer RA, Roman MJ, de Divitiis O, et al. Left ventricular mass and body size in normotensive children and adults: assessment of allometric relations and impact of overweight. J Am Coll Cardiol. 1992;20:1251-60.

22. Malina RM, Geithner CA. Body composition of young athletes. Am J Lifestyle Med. 2011;5:262-78.

23. Malina RM, Figueiredo AJ, Coelho-E-Silva MJ. Body size of male youth soccer players: 1978-2015. Sports Med. 2017:47:1983-92.

24. Valente-dos-Santos J, Sherar L, Coelho-E-Silva MJ, Pereira JR, Vaz V, CupidoDos-Santos A, et al. Allometric scaling of peak oxygen uptake in male roller hockey players under 17 years old. Appl Physiol Nutr Metab. 2013;38:390-5.

25. Roche AF, Thissen D, Chumlea W. Assessing the skeletal maturity of the hand-wrist: Fels method. Charles C Thomas: Springfield, Illinois; 1988.

26. Malina RM. Skeletal age and age verification in youth sport. Sports Med. 2011;41:925-47.

27. Lohman TG, Roche AF, Martorell R. Anthropometric standardization reference manual. Human Kinetics: Champaign, Illinois; 1988.

28. Slaughter MH, Lohman TG, Boileau RA, Horswill CA, Stillman RJ, Van Loan $M D$, et al. Skinfold equations for estimation of body fatness in children and youth. Hum Biol. 1988;60:709-23.

29. Castanheira J, Valente-Dos-Santos J, Costa D, Martinho D, Fernandes J, Duarte J, et al. Cardiac remodeling indicators in adolescent athletes. Rev Assoc Med Bras. 2017;63:427-34.

30. Devereux RB, Alonso DR, Lutas EM, Gottlieb GJ, Campo E, Sachs I, et al. Echocardiographic assessment of left ventricular hypertrophy: comparison to necropsy findings. Am J Cardiol. 1986;57:450-8.

31. Lang RM, Bierig M, Devereux RB, Flachskampf FA, Foster E, Pellikka PA, et al. Recommendations for chamber quantification: a report from the American Society of Echocardiography's guidelines and standards committee and the chamber quantification writing group, developed in conjunction with the European Association of Echocardiography, a branch of the European Society of Cardiology. J Am Soc Echocardiogr. 2005;18:1440-63.

32. Hopkins WG, Marshall SW, Batterham AM, Hanin J. Progressive statistics for studies in sports medicine and exercise science. Med Sci Sports Exerc. 2009; 41:3-13.

33. Kuczmarski RJ, Ogden CL, Guo SS, Grummer-Strawn LM, Flegal KM, Mei Z, et al. 2000 CDC growth charts for the United States: methods and development. Vital Health Stat 11. 2002;246:1-190.

34. Malina RM, Pena Reyes ME, Eisenmann JC, Horta L, Rodrigues J, Miller R. Height, mass and skeletal maturity of elite Portuguese soccer players aged 11-16 years. J Sports Sci. 2000;18:685-93.

35. Coelho E, Silva MJ, Figueiredo AJ, Simoes F, Seabra A, Natal A, Vaeyens R, et al. Discrimination of u-14 soccer players by level and position. Int J Sports Med. 2010;31:790-6.

36. Malina RM, Coelho E, Silva MJ, Figueiredo AJ, Carling C, Beunen GP. Interrelationships among invasive and non-invasive indicators of biological maturation in adolescent male soccer players. J Sports Sci. 2012;30:1705-17.

37. Valente-Dos-Santos J, Coelho-E-Silva MJ, Tavares OM, Brito J, Seabra A, Rebelo A, et al. Allometric modelling of peak oxygen uptake in male soccer players of 8-18 years of age. Ann Hum Biol. 2015;42:125-33.

38. Watson AM, Coutinho C, Haraldsdottir K, Brickson S, Dunn W, Eldridge M. Inseason changes in ventricular morphology and systolic function in adolescent female athletes. Eur J Sport Sci. 2018;18:534-40.

39. Csajagi E, Szauder I, Major Z, Pavlik G. Left ventricular morphology in different periods of the training season in elite young swimmers. Pediatr Exerc Sci. 2015;27:185-91.

40. Naylor LH, George K, O'Driscoll G, Green DJ. The athlete's heart: a contemporary appraisal of the "Morganroth hypothesis". Sports Med. 2008; 38:69-90.

41. Petek BJ, Wasfy MM. Cardiac adaption to exercise training: the female athlete. Curr Treat Options Cardiovasc Med. 2018;20:68.

42. Pela G, Crocamo A, Li Calzi M, Gianfreda M, Gioia MI, Visioli F, et al. Sexrelated differences in left ventricular structure in early adolescent nonprofessional athletes. Eur J Prev Cardiol. 2016;23:777-84. 
43. Batterham AM, George KP, Mullineaux DR. Allometric scaling of left ventricular mass by body dimensions in males and females. Med Sci Sports Exerc. 1997;29:181-6.

44. Welsman JR, Armstrong N. Scaling for size: relevance to understanding effects of growth on performance. In: Hebestreit $\mathrm{H}$, Bar-Or, editors. editors The Young Athlete. Oxford: Blackwell; 2008. p. 50-62.

45. Valente-Dos-Santos J, Coelho-E-Silva MJ, Ferraz A, Castanheira J, Ronque ER, Sherar $\mathrm{LB}$, et al. Scaling left ventricular mass in adolescent boys aged 11-15 years. Ann Hum Biol. 2014:41:465-8.

46. Beunen GP, Malina RM, Lefevre JA, Claessens AL, Renson R, Vanreusel B. Adiposity and biological maturity in girls 6-16 years of age. Int J Obes Relat Metab Disord. 1994;18:542-6.

47. Werneck AO, Conde J, Coelho-E-Silva MJ, Pereira A, Costa DC, Martinho D, et al. Allometric scaling of aerobic fitness outputs in school-aged pubertal girls. BMC Pediatr. 2019;19:96.

48. Coelho E, Silva MJ, Figueiredo AJ, Moreira Carvalho H, Malina RM. Functional capacities and sport-specific skills of 14-to 15-year-old male basketball players: size and maturity effects. Eur J Sport Sci. 2008;8:277-85.

49. Emmonds S, Morris R, Murray E, Robinson C, Turner L, Jones B. The influence of age and maturity status on the maximum and explosive strength characteristics of elite youth female soccer players. Sci Med Footb. 2017:1:209-15

50. Malina RM, Koziel SM. Validation of maturity offset in a longitudinal sample of polish girls. J Sports Sci. 2014;32:1374-82.

51. Malina RM, Choh AC, Czerwinski SA, Chumlea WC. Validation of maturity offset in the Fels longitudinal study. Pediatr Exerc Sci. 2016;28:439-55.

52. Maron BJ, Roberts WC, MCAllister HA, Rosing DR, Epstein SE. Sudden death in young athletes. Circulation. 1980;62:218-29.

53. Maron BJ, Epstein SE, Roberts WC. Causes of sudden death in competitive athletes. J Am Coll Cardiol. 1986;7:204-14.

54. Burke AP, Farb A, Virmani R, Goodin J, Smialek JE. Sports-related and nonsports-related sudden cardiac death in young adults. Am Heart J. 1991;121: 568-75.

55. Maron BJ, Isner JM, McKenna WJ. 26th Bethesda conference: recommendations for determining eligibility for competition in athletes with cardiovascular abnormalities. Task force 3: hypertrophic cardiomyopathy, myocarditis and other myopericardial diseases and mitral valve prolapse. J Am Coll Cardiol. 1994;24:880-5.

56. Sharma S, Maron BJ, Whyte G, Firoozi S, Elliott PM, McKenna WJ. Physiologic limits of left ventricular hypertrophy in elite junior athletes: relevance to differential diagnosis of athlete's heart and hypertrophic cardiomyopathy. J Am Coll Cardiol. 2002:40:1431-6.

57. Lozano-Berges G, Matute-Llorente A, Gomez-Bruton A, Gonzalez-Aguero A Vicente-Rodriguez G, Casajus JA. Accurate prediction equation to assess body fat in male and female adolescent football players. Int J Sport Nutr Exerc Metab. 2019:29:297-302.

\section{Publisher's Note}

Springer Nature remains neutral with regard to jurisdictional claims in published maps and institutional affiliations.

Ready to submit your research? Choose BMC and benefit from:

- fast, convenient online submission

- thorough peer review by experienced researchers in your field

- rapid publication on acceptance

- support for research data, including large and complex data types

- gold Open Access which fosters wider collaboration and increased citations

- maximum visibility for your research: over $100 \mathrm{M}$ website views per year

At $\mathrm{BMC}$, research is always in progress.

Learn more biomedcentral.com/submissions 